\title{
Educational emigration of Iranian and Tajik students to Russia: a comparative analysis
}

\author{
T. K. Rostovskaya ${ }^{1}$, Mehdi Afzali $^{1}$
}

1Institute for Demographic Research FCTAS RAS, 6 Fotieva str., p. 1, Moscow, 119333, Russian Federation

DOI: $10.18255 / 2412-6519-2021-4-416-429$

Research Article

Full text in Russian

Academic mobility of students is a complex phenomenon that plays an important role in the process of socio-economic and cultural development of receiving and sending countries. With the beginning of the globalization process, the movement of scientists, professors, students, etc. has become easier, faster, and more convenient, which has prompted universities and research institutions to attract students from abroad. Russia, like many other countries, has created the project «Development of the export potential of the Russian education system». However, there are different internal and external factors affecting the export process of Russian educational services. The purpose of this study is to compare the motives of foreign students from Iran and Tajikistan who chose Russia as a destination country to continue their education. This study uses a qualitative approach using open, semi-structured interviews with international students from Iran and Tajikistan. In total, 33 students from four cities and 6 different universities in Russia were interviewed with 21 men and 12 women aged 20 to 31 years old. The results of this study show that Iranian and Tajik students have much in common in terms of language, culture, values, and traditions but differ in their motives and decisionmaking process.

Keywords: Mobility, academic mobility, students, higher education, migration, Russia, Iran, Tajikistan

INFORMATION ABOUT THE AUTHORS

\begin{tabular}{r|l}
$\begin{array}{r}\text { Rostovskaya, Tamara K. } \\
\text { (correspondence author) }\end{array}$ & $\begin{array}{l}\text { E-mail: rostovskaya.tamara@mail.ru } \\
\text { Doc. Sc. (Sociology), Professor }\end{array}$ \\
Afzali, Mehdi & $\begin{array}{l}\text { E-mail: Mehdiafzali1991@gmail.com } \\
\text { Cand. Sc. (Sociology), Senior researcher }\end{array}$
\end{tabular}

Funding: RFBR, project No. 18-29-15043 MK.

For citation: Rostovskaya T. K., Afzali M. Educational emigration of Iranian and Tajik students to Russia: a comparative analysis // Social'nye i gumanitarnye znanija. 2021. Vol. 7, No 4. P. 416-429. (in Russ.)

(C) Rostovskaya T. K., Afzali M., 2021

This is an open access article under the CC BY license (https://creativecommons.org/licenses/by/4.0/) 


\title{
Образовательная эмиграция иранских и таджикских студентов в Россию: сравнительный анализ
}

\author{
Т. К. Ростовская ${ }^{1}$, Мехди Афзали ${ }^{1}$
}

${ }^{1}$ Институт демографических исследований ФНИСЦ РАН, ул. Фотиевой, дом 6, стр. 1, Москва, 119333, Российская Федерация

DOI: $10.18255 / 2412-6519-2021-4-416-429$

УДК 314.74

Научная статья

Полный текст на русском языке

Академическая мобильность студентов - сложное явление, которое играет важную роль в процессе социально-экономического и культурного развития принимающих и отпускающих стран. С началом процесса глобализации перемещение ученых, профессоров, студентов и т. д. стало проще, быстрее и удобнее, что побудило университеты и научные учреждения привлекать студентов из-за рубежа. Россия, как и многие другие страны, создала проект «Развитие экспортного потенциала российской системы образования». Однако существуют различные внутренние и внешние факторы, влияющие на процесс экспорта российских образовательных услуг. Цель данного исследования - сравнить мотивы иностранных студентов из Ирана и Таджикистана, которые выбрали Россию в качестве страны назначения для продолжения своего образования. В этом исследовании используется качественный подход с задействованием открытых полуструктурированных интервью с иностранными студентами из Ирана и Таджикистана. Всего было опрошено 33 студента из четырех городов и 6 различных университетов России, из них - 21 мужчина и 12 женщин в возрасте от 20 до 31 года. Результаты этого исследования показывают, что иранские и таджикские студенты, имеющие много общего с точки зрения языка, культуры, ценностей и традиций, различаются по своим мотивам и процессу принятия решений.

Ключевые слова: мобильность, академическая мобильность, студенты, высшее образование, миграция, Россия, Иран, Таджикистан

ИНФОРМАЦИЯ ОБ АВТОРАХ

Ростовская, Тамара Керимовна

(автор для корреспонденции)

Афзали, Мехди
E-mail: rostovskaya.tamara@mail.ru

Доктор социологических наук, профессор, заместитель директора по научной работе

E-mail: Mehdiafzali1991@gmail.com

Кандидат социологических наук, старший научный сотрудник

Финансирование: РФФИ, проект № 18-29-15043 мк

Для цитирования: Ростовская Т. К., Афзали М. Образовательная эмиграция иранских и таджикских студентов в Россию: сравнительный анализ // Социальные и гуманитарные знания. 2021. Том 7, № 4 . С. 416-429.

(C) Ростовская Т. К., Афзали М., 2021

Статья открытого доступа под лицензией СС BY (https://creativecommons.org/licenses/by/4.0/) 


\section{Введение}

Академическая мобильность - сложное социально-экономическое, политическое, культурное и психологическое явление, которое можно рассматривать с разных точек зрения в процессе миграции. В ходе глобализации академическая мобильность стала одним из важных факторов, который способствует развитию и росту профессионального уровня населения принимающих стран. Хотя существуют разные подходы к определению академической мобильности, как правило, она понимается как «период обучения, преподавания и / или исследования в стране, отличной от страны проживания студента или академического сотрудника (отныне именуется «родной страной») [1]. Академическая мобильность имеет прямое отношение к процессу интернационализации образовательных услуг в странах и университетах.

Процесс интернационализации образовательных услуг сделал перемещение ученых, профессоров, студентов и т. д. проще, быстрее, удобнее, продвигая различные образовательные программы для привлечения академического персонала и особенно студентов из других стран. В международном масштабе это повысило межкультурную терпимость, межкультурное понимание, знания, навыки, ценности и т. д., а также способствовало образовательному партнерству между странами. Студенты как основная группа академической мобильности играют важную роль в социально-экономическом и культурном развитии принимающих и отпускающих стран.

Студенческая мобильность имеет разное значение для университетов и студентов [2]. Университеты стараются привлекать лучших иностранных студентов, чтобы повысить свой мировой рейтинг. В развитых странах привлечение иностранных студентов способствует развитию экономики, основанной на знаниях, и положительно влияет на качество образования в университетах [3]. Студенты посредством образовательного и культурного обмена получают возможности для саморазвития и самореализации, знакомятся с другими культурами, новыми людьми, изучают иностранные языки, что делает их более социализированными в обществе [4]. Таким образом, мобильность студентов является очень важной характеристикой в процессе интернационализации университетов и стран, которая дает студентам новые знания и профессиональные навыки.

Чтобы иметь возможность эффективно использовать преимущества мобильности студентов, устанавливать личные связи и дальнейшее сотрудничество, должно быть налажено надлежащее взаимодействие между странами, университетами, партнерами по образованию, культурами, традициями и студентами.

Цель данного исследования - сравнить мотивы иностранных студентов из Ирана и Таджикистана, которые выбрали Россию в качестве страны назначения для продолжения своего образования. Сравнение в этом исследовании построено с трех точек зрения: причины эмиграции из родной страны (факторы выталкивания), причины выбора России в качестве страны назначения (факторы притяжения) и выбор конкретного университета. В этом исследовании мы выбрали студентов из Ирана и Таджикистана, поскольку у этих двух стран много общего, например язык, культура и традиции. 


\section{Методология}

В данном исследовании применяется качественный подход с использованием открытых полуструктурированных интервью иностранных студентов из Ирана и Таджикистана. Респонденты обучаются на очной форме в ведущих университетах Москвы, Санкт-Петербурга, Астрахани и Казани. Всего было опрошено 33 студента из четырех городов и 6 различных университетов, в гендерном разрезе: 21 мужчина и 12 женщин в возрасте от 20 до 31 года. В основном они изучали стоматологию, общую медицину, инженерные, гуманитарные и социальные науки. Десять студентов из Таджикистана и один студент из Ирана получали стипендии от правительства России, а остальные оплачивали свое обучение. Данные интервью были собраны в апреле 2021 года. Интервью проводились при личностном контакте либо онлайн через Zoom, на персидском и русском языке. Средняя продолжительность интервью составила 51 минуту (минимальная - 29 минут, максимальная - 73).

В ходе интервью задавались вопросы, аналогичные использованным в исследовании А. Нефедовой «Почему иностранные студенты выбирают обучение в ведущих университетах России». Поскольку имеющаяся литература о мотивации иностранных студентов, которые выбирают обучение в России, минимальна, автор использовала результаты интервью с иностранными студентами, чтобы выяснить, что привело их в Россию. Как и в исследовании А. Нефедовой, в нашей работе также используется теория притяжения-выталкивания, чтобы выяснить, что приводит иранских и таджикских студентов в Россию. Таким образом, сходство методов, использованных в этих двух исследованиях, дает более глубокое понимание того, почему иностранные студенты выбирают для обучения РФ.

Интервью включало следующие разделы: предыдущий опыт обучения, процесс принятия решений, процесс получения информации, процесс подачи заявки, процесс отбора, процесс обучения, место проживания, учебный план и плата за обучение. Интервью внимательно выслушивались и записывались, и каждая строчка тщательно анализировалась. Ответы, относящиеся к нашей теме, были определены и помечены. Затем сравнивались сходства и различия результатов, и ответы распределялись по категориям. Все результаты были показаны участникам, чтобы они могли оценить достоверность и надежность этих кодов.

\section{Политика России в области экспорта образовательных услуг}

Развитие сотрудничества между странами в области высшего образования в целом и академической мобильности в частности - сложный многомерный процесс. На высококонкурентном глобальном рынке образовательных услуг академическая мобильность - яркий символ современного мира и важный индикатор глобальных миграционных процессов. Для повышения эффективности миграционной политики России в условиях нынешнего переформатирования системы международных отношений разработан проект «Развитие экспортного потенциала российской системы образования» [5]. Это привело к увеличению привлечения иностранных студентов из стран СНГ и дальнего зарубежья.

Согласно статистическому изданию «Экспорт российских образовательных услуг», в 2017/2018 учебном году количество иностранных студентов, обучающихся в российских вузах, составляло 334,5 тыс. чел. Почти 77 \% от общего числа иностранных студентов ( 257 тысяч студентов) в России обучаются на очной форме, что примерно в пять раз больше показателей 1995/1996 учебного года, 
остальные 23 \% обучаются на заочной форме. Россия - основная страна назначения для иностранных студентов из СНГ. В 2017/2018 гг. почти 53 \% иностранных студентов, обучающихся по очной форме обучения в России, прибыли из стран СНГ, Грузии, Абхазии и Южной Осетии, примерно 25,1 \% - из стран Азии, 8,6 \% - из стран Ближнего Востока и Северной Африки, 5,7 \% - из стран Африки к югу от Сахары, 2,5\% - из стран Западной Европы, 2,1\% - из Латинской Америки, 1,3 \% - из восточноевропейских и балканских стран, 0,8\% - из Северной Америки и Океании, 0,6 \% из стран Балтии и 0,3 \% - из стран Северной Европы [7]. Студенты из Казахстана, Туркменистана, Узбекистана, Таджикистана и Украины составляют, соответственно, 12,3 \%, 6,5 \%, 5 \%, 5 \% и 3,8 \% от общего числа иностранных студентов в России.

Хотя количество иранских студентов в российских вузах за последние десять лет увеличилось почти в 6 раз и в 2017/2018 гг. достигло 2,7 тыс. чел., на них приходится всего $1 \%$ от общего числа иностранных студентов и $6 \%$ от общего числа студентов из стан Азии (в издании «Экспорт российских образовательных услуг» Иран классифицируется как азиатская страна). Это показывает, что доля таджикских студентов в общем количестве иностранных студентов в российских университетах примерно в 10 раз больше, чем иранских.

Ежегодно правительство России выделяет определенную квоту для иностранных студентов на обучение в российских вузах со стипендиями. В 2017/2018 учебном году было выделено 12183 таких квоты. Наибольшая их доля пришлась на страны Азии (29,9\%), СНГ (28,7 \%), Африки южнее Сахары $(12,7$ \%), Ближнего Востока и Северной Африки $(11,0$ \%). Восточно-европейским и балканским странам было выделено 7,35 \% «бюджетных» квот, странам Латинской Америки - 5,5 \%, Балтии - 2,4 \%, Западной Европы - 2,1 \%. Наименьшая доля «бюджетных» мест пришлась на страны Северной Европы (0,2 \%), а также Северной Америки и Океании $(0,2 \%)$ [7].

В 2017/2018 гг. квоту на обучение в России получили 618 таджикских студентов, что составляет примерно 5 \% от общего количества квот и 17,3 \% от квот, полученных странами СНГ, Грузией, Абхазией и Южной Осетией, которая показывает снижение на 3 \% за последние 5 лет. С другой стороны, только 90 иранских студентов получили квоты, что составляет всего 0,7 \% от общего числа квот и примерно 2,6 \% квот, полученных азиатскими странами, которые показывают рост на 0,6 \% с 2005 года. Из 2,7 тыс. иранских студентов в России почти 91 \% студентов (2,5 тыс.) учились на платной основе.

Исследование, проведенное А. Нефедовой, показывает, что мотивы студентов из стран СНГ и дальнего зарубежья при выборе России в качестве страны назначения для продолжения образования различны. Студенты из стран СНГ выбрали Россию, потому что у них там либо родственники, либо друзья, либо они сделали свой выбор, основываясь на собственных знаниях. С другой стороны, студенты из стран дальнего зарубежья считали, что Россия является относительно небезопасной страной, и что она не была их первым выбором при получении образования, поэтому их мотивация и процесс отбора иные. Более того, они почти не рассматривают для учебы другие города, кроме Москвы или Санкт-Петербурга. В том же исследовании выявлены другие проблемы, препятствующие привлечению иностранных студентов в Россию, такие как правовые ограничения при приеме на работу, неблагоприятная правовая база, снижение интереса к русскому языку, небольшое количество 
образовательных программ на английском языке и плохая репрезентация российских университетов в Интернете [6].

Высокая численность молодежи в Таджикистане обусловливает высокий спрос на высшее образование, что делает эту страну одним из перспективных рынков для российских образовательных услуг. Высокий уровень безработицы в Таджикистане вынуждает большое количество молодых людей эмигрировать, и Россия считается одним из основных и наиболее желанных направлений для эмиграции. Сложившиеся между Таджикистаном и Россией отношения способствовали заключению межгосударственных, межправительственных и межведомственных соглашений, позволяющих таджикским студентам поступать в российские вузы с бюджетной формой обучения.

Несмотря на то, что отношение к России в Таджикистане ухудшается, многие его граждане оценивают РФ как дружественную страну. У многих таджикских семей есть родственники в России, с которыми они поддерживают постоянный контакт. Знание русского языка и культуры таджикским населением, а также более высокое качество образования побуждают таджикских студентов выбирать для учебы Россию [8]. Неконкурентоспособная система образования в Таджикистане и невозможность обучаться по многим специальностям также рассматриваются как факторы, влияющие на эмиграцию студентов из Таджикистана [9].

Эмиграция квалифицированной рабочей силы и студентов из Ирана также связана с высоким уровнем безработицы. Качество образования в области науки или техники в Иране довольно высокое. Выпускники бакалавриата и магистратуры могут легко поступить в западные или восточные университеты, включая Европу, Японию и Сингапур. Главными причинами эмиграции студентов из Ирана являются сложные вступительные экзамены в университеты и обязательная двухлетняя военная служба для мужчин. Многие студенты, не сдавшие экзамен, предпочитают эмигрировать, чтобы избежать военной службы. Даже те, кто поступил в иранские университеты, разочарованы социально-политическим давлением внутри университетов [10]. В исследовании 2018 г., проведенном А. Каземи и др. и посвященном иранским студентам в Малайзии, было установлено, что отсутствие социальной свободы и лишения являются толчком к их эмиграции, в то время как политическое давление не оказывает существенного влияния на эмиграцию. Незначительное влияние на эмиграцию студентов также оказывает ситуация со свободой слова и вероисповедания [11].

\section{Полученные результаты}

Чтобы сравнить и выяснить сходства и различия, результаты наших исследований представлены в двух разделах. Мы разделили наши выводы на две группы: для иранских студентов и для студентов из Таджикистана. И каждая группа имеет три подкатегории, включая процесс принятия решения об обучении за границей (факторы выталкивания), процесс выбора России в качестве страны назначения для продолжения образования (факторы притяжения) и выбор российского университета. 


\section{Иранские студенты, обучающиеся в России}

Процесс принятия решения об обучении за границей (бакторы выталкивания). Доступ к образованию в Иране не ограничен, в 2017/2018 учебном году более 3,6 миллиона студентов обучались на разных уровнях в высших учебных заведениях Ирана [12]. Однако доступ в лучшие государственные университеты, которые являются бесплатными, высоко конкурентен. Студентам бакалавриата, магистратуры и докторантуры необходимо сдать сложный вступительный экзамен под названием «Конкур». Ежегодно этот экзамен сдают более 1 миллиона студентов. Чтобы поступить в хорошие университеты, особенно по медицинским и инженерным специальностям, студенты должны входить в 1,000 лучших студентов страны. Поэтому многие студенты, которые не могут получить желаемое образование в конкретном университете и конкретном городе, вынуждены эмигрировать на учебу за границу.

Когда мне было 18 лет, мне нужно было сдать вступительный экзамен, чтобы поступить в университет. Посещать любой университет Тегерана, чтобы изучать стоматологию, для меня было невозможно из-за того, что я не входил в 300 лучших студентов страны. Мой рейтинг на экзамене «Конкур» составил 45,000 по стране, что не дает мне возможности изучать стоматологию ни в одном университете Ирана.

В Иране у мужчин ситуация с поступлением в университет более сложная и ограниченная. Каждый мужчина в Иране должен пройти обязательную военную службу в течение почти 2 лет. После школы ученики должны заявить о своем военном статусе. Таким образом, у них есть один или два года для поступления в университет, а если не могут, они должны пойти служить в армию. Поэтому одним из основных факторов, влияющим на эмиграцию иранских студентов мужского пола, является военная служба.

Я очень усердно учился для экзамена «Конкур», но в первый год не смог поступить ни в один университет. На втором курсе я начал учиться, но думал, что не смогу попасть на желаемую программу в моем городе и, конечно, я никогда не планировал служить в армии. Я внес залог в размере 5,000 долларов США, чтобы уехать из страны, потому что в тот год я должен был стать солдатом. После этого я ни разу не вернулся в Иран за последние 4 года.

Еще одна проблема иранских университетов - это гендерная дискриминация и очень тяжелая атмосфера в образовательной среде. По некоторым специальностям количество мест для мужчин и женщин неравное. Более того, в университетах из-за менталитета религиозных групп женщины подвергаются давлению по поводу того, какая у них одежда и макияж.

Я проучилась два года в университете в городе Мешхед, за эти годы более десяти раз меня останавливали религиозные группы из-за моей одежды, моего макияжа и моего головного убора. Дважды я не смогла войти в университет. Есть некоторые профессора, которые не хотели сотрудничать со мной, потому как считали, что я этого не достойна из-за моего внешнего вида. Итак, я ушла из университета, когда мне 
было 20 лет. Примерно один год я пробыла дома, а потом моя семья согласилась отправить меня в Россию, хотя они очень боялись это сделать.

Экономическая ситуация в Иране за последние десятилетия постоянно ухудшается. По данным статистического центра Ирана, в 2021 году уровень безработицы составит почти 12 \%. В каждой семье можно найти человека образованного и не имеющего работы. Более того, одна из главных проблем заключается в том, что многие люди без оптимизма смотрят в будущее. Они считают, что социально-экономическая ситуация в Иране в ближайшее время не изменится.

В моей семье двое моих братьев остались без работы, один из них имеет степень магистра социальных наук, а другой - инженер, оба безработные. Я решил покинуть Иран, потому что хотел осуществить свои мечты в другой стране. Я не думаю, что вернусь в Иран, потому что считаю, что социально-экономическая ситуация в моей стране не соответствует моим амбициям, и не думаю, что ситуация изменится в ближайшем будущем.

Процесс выбора России как страны назначения для продолжения образования (факторы притяжения). Хотя от наших иранских студентов поступило много ответов о выборе России в качестве страны назначения для продолжения учебы, некоторые ответы повторялись чаще, чем другие. Например, более простой процесс подачи заявления на визу, дипломы некоторых российских университетов были приняты Министерством здравоохранения и медицинского образования Ирана и Министерством науки, исследований и технологий, простые университетские требования, отсутствие требований сертификатов о знании английского языка (например IELTS и TOEFL) и более низкая плата за обучение, чем в европейских или американских университетах. Поскольку Иран уже много лет находится под международными санкциями, получение визы - очень сложная задача для иранцев. Многие студенты, несмотря на то, что у них были приглашения от европейских и американских университетов, в процессе оформления визы получили отказ. Однако оформить заявку на визу для въезда в Россию очень просто и удобно.

Когда я получил приглашение из университета в России, я поехал в посольство России, которое находится в Тегеране, мне нужно было получить визу в очень короткие сроки. Я получил визу всего за 2 дня, но мне пришлось доплатить деньги за это. Другие мои друзья также получили визы не более чем за неделю без каких-либо проблем или странных требований.

Если иранский студент, получивший образование за границей, возвращается в Иран, чтобы работать на родине, его / ее диплом, полученный за границей, должен быть заверен либо Министерством здравоохранения и медицинского образования Ирана, либо Министерством науки, исследований и технологий. Каждый год эти министерства предоставляют список с названиями университетов в других странах, дипломы которых признаются ими. Это означает, что только те студенты, которые получили свои дипломы в перечисленных университетах, могут подтвердить свои степени и получить иранский эквивалентный диплом (в некоторых случаях им 
необходимо сдать несколько предметов, чтобы иметь возможность получить эквивалентный диплом).

Я всегда хотел изучать стоматологию в другой стране, где мои дипломы будут приняты на моей Родине, потому что, когда я закончу учебу, я хочу работать в Иране. Агент, который послал меня в Россию, сказал мне, что здесь есть несколько университетов, которые принимаются Министерством здравоохранения и медицинского образования.

Многие из иранских студентов, обучающихся в российских университетах, не могут нормально говорить по-английски, у них нет сертификатов на знание языка и хорошей академической подготовки и результатов. Поэтому они ищут университеты без каких-либо из этих конкретных требований.

Я знаю, что во многих российских вузах требуется сертификат о знании английского языка, но у меня его не было. Мой агент сказал мне, что, заплатив взятку, он может зарегистрировать меня в университете без каких-либо особых требований.

Более того, обучение в России для иранских студентов считается относительно дешевым, если сравнивать оплату за обучение с европейскими или американскими университетами. Более того, расходы на проживание в городах России считаются более дешевыми, чем во многих городах Европы и Америки.

Сначала я хотел поехать в Чехию учиться, но помню, что это было очень дорого, почти 12000 евро в год на оплату за обучение. А расходы на проживание составляли в среднем 650 евро в месяи. В России это намного дешевле, особенно в Санкт-Петербурге в сравнении с Москвой.

Более того, во время наших интервью с иранскими студентами было еще несколько ответов, подтверждающих результаты исследования, проведенного А. Нефедовой. Например, многие иранские студенты говорили о том, что их родители боялись отправлять их в Россию. Они считали Россию опасной страной с агрессивными людьми. В некоторых случаях родители до сих пор считают Россию коммунистической страной. Кроме того, иранские студенты, обучающиеся в России, поскольку они учатся на английском языке и не могут свободно или должным образом говорить на русском языке, в некоторых случаях подвергались ненадлежащему обращению к себе со стороны российских граждан в общественных местах.

Подбор российского вуза. Иранские студенты не прилагают усилий, чтобы выбрать себе подходящий университет. Хотя в Интернете имеется много информации о российских университетах на персидском языке, студенты в основном ищут информацию об условиях жизни в России, а не о качестве образования. Студенты обычно ищут университеты, которые уже одобрены Министерством здравоохранения и медицинского образования и Министерством науки, исследований и технологий. Все наши иранские собеседники упомянули, что они подавали заявки в университеты через агентов или других иранских студентов в России, которые работают агентами. Агенты обычно поддерживают студентов от встречи в аэропорту до регистрации и подачи заявления на визу. Средняя цена, которую студенты платят агентам, составляет 1300 долларов США или евро. 
Когда я хотел поступить в университет, мне было трудно это сделать. Более того, это был мой первый выезд из страны, поэтому я подумал, что мне нужен кто-то, кто мог бы поддержать меня в новой стране. Я уже знал, какие университеты принимаются Министерством здравоохранения и медицинского образования, поэтому я решил подать заявку через агентов, которые могли мне оказать услуги. Я заплатил 1400 долларов США. 700 долларов США я заплатил в Иране, а 700 - после того, как получил визу в университете.

Некоторые из наших собеседников выбрали конкретную программу в конкретном университете, но агенты их не одобряли. Им сказали, что в этот университет невозможно поступить или что университет предлагает программу только на русском языке, что было неверной информацией, предоставленной агентами по их личным соображениям. Более того, те респонденты, которые хотели эмигрировать в Европу или Америку после получения образования в России, отметили, что они были заинтересованы в поступлении в университеты, чей мировой рейтинг в системе QS ниже 500.

\section{Таджикские студенты, обучающиеся в России}

Процесс принятия решения об обучении за границей (факторы выталкивания). Одна из основных проблем Таджикистана заключается в том, что студенты университетов имеют ограниченный доступ к современным технологиям и инструментам. Не только учебные помещения и требования устарели, но и условия повседневной жизни студентов в таджикских университетах очень ограничены, недостаточны или имеют низкое качество.

Одна из причин, по которой я эмигрировал из Таджикистана, заключается в том, что мне не нравится университетская среда. У нас нет хороших технологий или новых инструментов. Например, я хочу быть инженером, но машинное оборудование в наших университетах очень старое или его количество недостаточно. Некоторые из наших университетов даже имеют очень ограниченный доступ к спортивным сооружениям, общежитиям и т. д.

Качество образования в таджикских университетах изменилось за последние 25 лет. После распада Советского Союза в 1990-х годах началось формирование новой образовательной системы, отвечающей международным требованиям, основанной на национальных ценностях, культуре и традициях, однако прогресс в изменениях был очень медленным [13]. Качество образования по многим программам очень низкое, преподавательский состав плохо подготовлен, а методы, используемые в некоторых программах, очень старые. Таким образом, рейтинг университетов и институтов высшего образования Таджикистана в мире очень низкий.

Я учился на бакалавриате в Таджикском государственном национальном университете, во время учебы мы могли наблюдать, что многие профессора не имели должного образования. Книги, статьи, методы и обсуждения взяты из очень старых источников. Исследованиям уделялось гораздо меньше внимания, чем в России. Профессора, которые не были хорошо образованы или хорошо подготовлены, были еще более 
несправедливы, выставляя хорошие оценки, что делало учебную среду очень неприятной.

Хотя экономическая ситуация в Таджикистане с точки зрения безработицы (7,5 \%) и инфляции (6 \%) [14] намного лучше, чем в Иране, студенты из Таджикистана очень пессимистично относятся к поиску работы на родине после окончания университетов. Они считают, что для того, чтобы найти работу в Таджикистане, вы должны знать кого-то, кто мог бы помочь вам в процессе трудоустройства. Это означает: если у вас нет никаких связей, вы не сможете найти работу, что заставляет людей эмигрировать в Россию, как это сделали другие члены их семей.

Я считаю, что найти работу в Таджикистане очень сложно, более того, вы не сможете найти подходящую работу с достойной зарплатой, если у вас нет связей с кем-то, кто уже где-то работает. Трое моих двоюродных братьев после 3 лет работы в Душанбе эмигрировали в Москву. Я подумал, зачем мне тратить время в Таджикистане, поэтому я приехал в Москву, чтобы найти работу и помочь своей семье в Таджикистане.

Одним из факторов, побуждающим студентов эмигрировать из Таджикистана, является то, что они, как правило, не чувствуют себя комфортно в местной социальной атмосфере. Они отметили, что уровень жизни как у студентов в России у них выше, чем в Таджикистане. Хотя они столкнулись в России со многими проблемами, такими как дискриминация или расизм, они считают, что живут в России более комфортно и расслабленно с социальной точки зрения. Некоторые из наших собеседников считали, что даже с религиозной точки зрения они чувствуют себя свободнее.

Теперь, когда я приехал в Россию, я больше думаю о том, как мне было неуютно в моей стране. Помню, в то время мне всегда приходилось делать религиозные вещи, которые мне говорили делать родители. Отношения с девушками были под пристальным вниманием. У нас было не так уж и весело, и жизнь была такой рутинной.

Процесс отбора России как страны назначения для продолжения образования (факторы притяжения). Выбор России в качестве страны назначения для продолжения образования или работы - явление не новое для людей из стран СНГ. Традиционно в последние десятилетия миллионы иммигрантов прибывают в Россию из государств СНГ, поэтому существует особая социально-экономическая сеть среди людей в странах происхождения и тех, кто живет в РФ. Наличие членов семьи и родственников в России побуждает других людей в родных странах переезжать в РФ. При этом они получают поддержку родственников, помогающих адаптироваться в России.

Я приехал в Россию, потому что мой брат и двое моих двоюродных братьев живут в Москве, они уехали в Россию в 2016 году. Когда они приехали навестить семью в Таджикистане, они объяснили ситуацию с Москвой, университетами и т. д., так что приезд в Россию был для меня менее рискованным, потому что я знал, что там мне могут помочь, если я столкнусь с какой-либо проблемой. Кроме того, когда 
я учился в школе в Таджикистане, некоторые из моих учителей окончили университеты в России. В Таджикистане везде, где вы видите, можно найти кого-то, кто так или иначе связан с Россией.

Более того, многие студенты из Таджикистана выбрали Россию, потому что после окончания учебы хотят жить и работать в РФ. Многие из них, пока учатся, работают и материально помогают своим семьям в Таджикистане.

Многие мои друзья работают в России, они приехали сюда давно, работают в такси и на стройке. Я приехал сюда, потому что думал, что мне легче найти работу, чем в моей стране, сейчас я учусь и подрабатываю в службе доставки. После окончания учебы планирую работать в строительной сфере.

Поскольку десять таджикских студентов, участвовавших в нашем исследовании, учились на стипендии, результаты наших интервью показывают, что стипендия для таджикских студентов была одним из основных факторов, побуждающих их учиться в России.

Правительство России предоставляет стипендии многим людям со всего мира. Я смог получить место по квоте, поэтому я переехал сюда.

Более того, во время наших интервью были другие ответы, влияющие на студентов из Таджикистана, желающих учиться в России, такие как знание языка, поскольку многие из них уже могли говорить на русском языке, а также общее понимание и знакомство с русской культурой, окружающей средой и людьми.

Подбор российского вуза. Выбор вуза для студентов из Таджикистана кажется несложной задачей. Доступ к информации о российских университетах на русском языке позволяет студентам найти достаточную информацию о желаемой программе, степени и университете. Однако наиболее важным фактором при выборе вуза для таджикских студентов являются члены семьи или родственники. Это означает, что предоставляемая ими информация играет важную роль в процессе принятия решений. Таджикские студенты предпочитают узнавать об образовании и условиях жизни в России от своих знакомых и членов таджикских миграционных сетей. Однако они предпочитают учиться в университетах, расположенных в крупных городах, таких как Москва и Санкт-Петербург, чтобы легче было найти работу.

Я знал, что хочу изучать гуманитарные науки в Москве, поэтомуя искал несколько университетов и ознакомился с ними. Однако, чтобы лучше понимать стоимость обучения, условия проживания, атмосферу обучения, задавал вопросы своим таджикским соотечественникам, которые уже учились в российских вузах.

Другими критериями выбора вуза, упомянутыми таджикскими респондентами, являются стоимость обучения, близость к месту проживания членов семьи или родственников, рейтинг вузов в QS и более качественные условия для обучения. 


\section{Заключение}

В данном исследовании сравниваются мотивы эмиграции из Ирана и Таджикистана, а также обсуждается процесс принятия решений при выборе страны и вуза. Иранские и таджикские студенты, имеющие много общего с точки зрения языка, культуры, ценностей и приверженности своим национальным традициям, различаются по своим мотивам и процессу принятия решений.

Картина эмиграции студентов из Ирана показывает, что если, например, в последние десятилетия иранцы переехали в Европу или Америку для обучения в высококачественных университетах, то сегодня, особенно с 2009 года, после протестов из-за президентских выборов, эмиграция студентов из Ирана в основном вызвана тем, что они просто хотели убежать от таких проблем, как вступительные экзамены в университет, военная служба, гендерная дискриминация и т. д. Кроме того, они редко ищут высококачественные университеты. Многие студенты не могут поступить в такие вузы, так как они не соответствуют их академическим и языковым требованиям. Причины, по которым они выбрали Россию в качестве страны назначения для обучения, ограничиваются такими факторами, как низкая плата за обучение, легкий процесс получения визы и поступления в университет. Во время наших интервью мы почти не заметили такого важного фактора при выборе университета, как качество образования. Более того, поскольку иранские студенты не знают русского языка, они предпочитают работать с посредниками, агентами и т. д., что стоит им денег, а иногда сталкиваются с неверной информацией о стране, университете, людях, культуре и т. д.

С другой стороны, студенты из Таджикистана традиционно эмигрируют в Россию, потому что у них много семей и родственников, которые уже живут в российских городах. Они уезжают из-за плохой инфраструктуры в их университетах, низкого качества образования, необразованных и неподготовленных профессоров, учителей, методик, книг и т.д. Многие студенты также некомфортно чувствуют себя в Таджикистане в социальном и религиозном плане. В отличие от иранских студентов студенты из Таджикистана, которые планируют эмигрировать в третью страну или вернуться домой, намерены работать в России. Они хотят продолжить учебу в России, потому что им легче устроиться на работу во время учебы в университетах или после их окончания. Поэтому они вслед за родителями, членами семьи, родственниками уезжают в Россию, чтобы в будущем как-то помочь своим семьям в Таджикистане.

\section{Ссылки / References}

1. Recommendation № R (95) 8 of the Committee of Ministers to Member States on Academic Mobility (Adopted by the Committee of Ministers on 2 March 1995 at the 531st meeting of the Ministers' Deputies) // Council of Europe. 02.03.1995. URL: https://rm.coe.int/16804e4d00 (дата обращения: 20.05.2021).

2. The Dynamics of International Student Circulation in a Global Context / Agarwal, Pawan \& Said, Mohsen \& Sehoole, Molatlhegi \& Sirozi, Muhammad \& de Wit, Hans. Brill-Sens, 2007. P. 109-144. DOI:10.1163/9789087903169_006. 
3. Interim evaluation of Erasmus Mundus II (2009-2013): Final Report // European commission. 19.09.2012. URL:

http://ec.europa.eu/transparency/regdoc/rep/1/2012/EN/1-2012-515-ENF1- 1.Pdf (дата обращения: 20.05.2021).

4. Socialization of a personality under the conditions of globalization and informatization of the society / M. G. Sergeeva, L. Z. Karavanova, M. A. Bereznatskaya, K. E. Klychkov,

T. E. Loktionova, V. A. Chauzova // Espacios. 12.02.2018. URL:

http://www.revistaespacios.com/a18v39n21/a18v39n21p28.pdf (дата обращения: 20.05.2021).

5. Russian-Chinese Academic Mobility As Competitive Partnership / S. Ryazantsev, S. Shakhray, A. Yanick, S. Popova // Herald of the Russian Academy of Sciences. 2020. № 90 (1). P. 15-24. DOI:10.1134/S1019331620010128.

6. Nefedova A. Why International Students Choose to Study at Russia's Leading Universities // Journal of Studies in International Education. October 2020. P. 1-16. DOI:10.1177/1028315320963514.

7. Экспорт российских образовательных услуг // Министерство науки и высшего образования Российской Федерации. URL:

https://www.5top100.ru/documents/library/113494/ (дата обращения: 20.05.2021).

8. Голомидова П. С. Экспорт российского высшего образования в Таджикистане: потенциал и перспективы. // Социология и общество: традиции и инновации в социальном развитии регионов. Сборник докладов VI Всероссийского социологического конгресса (Тюмень, 14-16 октября 2020 г.). М.: РОС; ФНИСЦ РАН, 2020. C. 5604-5613. DOI:10.19181/kongress.2020.659.

9. Ризоён Ш. Ш. Внешняя образовательная миграция молодежи Таджикистана как двухуровневый ресурс «мягкой силы» // Научный журнал «Дискурс Пи». 2021. № 1 (42). C. 158-175. DOI:10.24412/1817-9568-2021-1-158-175.

10. Kamyab S. Flying Brains: A Challenge Facing Iran today // International Higher Education. 2007. № (47). P. 23-24. DOI:10.6017/ihe.2007.47.7955.

11. Contributing Factors to Migration Growth Among Iranian Students: Drivers of Migration to Malaysia / A. Kazemi, A. Baghbanian, M. M. Maymand et al. // Int. Migration \& Integration. 2018. № 19. P. 757-770. DOI:10.1007/s12134-018-0567-z.

12. Statistics of Education and research // Statistical center of Iran. URL: https://www.amar.org.ir/english (дата обращения: 20.05.2021).

13. DeYoung A. J., Kataeva Z., Jonbekova D. Higher Education in Tajikistan: Institutional Landscape and Key Policy Developments. In: Huisman J., Smolentseva A., Froumin I. (eds) 25 Years of Transformations of Higher Education Systems in Post-Soviet Countries // Palgrave Studies in Global Higher Education, Palgrave Macmillan. 25.04.2018. P. 482. https://doi.org/10.1007/978-3-319-52980-6_14

14. Unemployment and inflation rate of Tajikistan // World bank data. URL:

https://data.worldbank.org/country/tajikistan (дата обращения: 20.05.2021). 